\title{
Erratum
}

\section{Building a mouse model hallmarking the congenital human cytomegalovirus infection in central nervous system}

\author{
J. Tang et al. [Arch Virol (2002) 147: 1189-1195] \\ DOI 10.1007/s00705-002-0797-3
}

On p. 1189 in above-mentioned paper, some of the authors' names were printed incorrectly. Authors should be cited as follows:

J. L. Tang, M. L. Wang, J. J. Qiu, D. Wu, W. Hu, B. F. Shi, Y. Hu, and J. P. Li

Besides, Dr. Hu's Institutional Address is not Pathological Department, but The Microbiology Teaching and Researching Section, Anhui Medical University, Hefei, China. 